RECEIVED

APR 81977

F. PATENT GROUP

\title{
TRANSITION TEMPERATURE OF ISOTROPIC SUPERCONDUCTORS
}

\author{
S. J. Poon
}

APRIL 1976

A REPORT ON RESEARCH CONDUCTED UNDER CONTRACT FOR THE U.S. ENERGY RESEARCH AND DEVELOPMENT ADMINISTRATION

IDEMTIFIED DOCU:AEUT(S) PEVIEWED PATENTWISE: NO OBECION IS RIEEDOSED F.ON THE PATENT STANDPOINT TO PUDLCATION THEREOF.

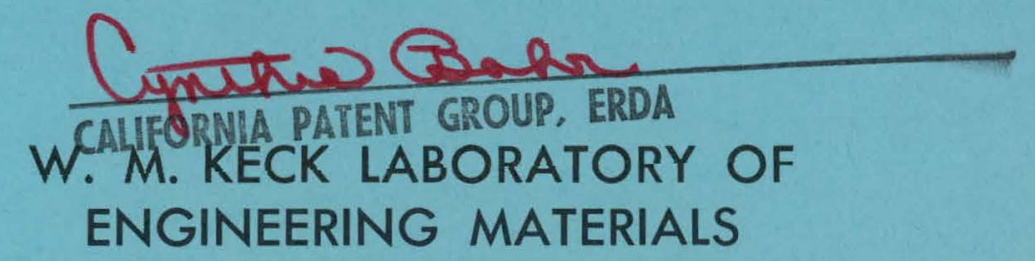

CALIFORNIA INSTITUTE OF TECHNOLOGY

PASADENA 


\section{DISCLAIMER}

This report was prepared as an account of work sponsored by an agency of the United States Government. Neither the United States Government nor any agency Thereof, nor any of their employees, makes any warranty, express or implied, or assumes any legal liability or responsibility for the accuracy, completeness, or usefulness of any information, apparatus, product, or process disclosed, or represents that its use would not infringe privately owned rights. Reference herein to any specific commercial product, process, or service by trade name, trademark, manufacturer, or otherwise does not necessarily constitute or imply its endorsement, recommendation, or favoring by the United States Government or any agency thereof. The views and opinions of authors expressed herein do not necessarily state or reflect those of the United States Government or any agency thereof. 


\section{DISCLAIMER}

Portions of this document may be illegible in electronic image products. Images are produced from the best available original document. 
California Institute of Technology W. M. Keck Laboratory of Engineering Materials

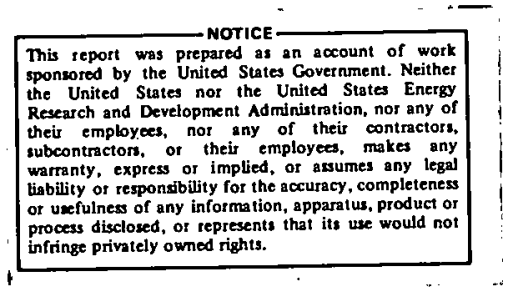

Energy Research and Development Agency Report No. 72 under Contract No. AT $(04-3)-822$

Professor Pol Duwez, principal investigator. 


\section{NOTICE}

This report was prepared as an account of work sponsored by the United States Government. Neither the United States nor the Energy Research and Development Administration, nor any of their employees, nor any of their contractors, subcontractors, or their employees, makes any warranty, express or implied, or assumes any legal liability or responsibility for the accuracy, completeness or usefulness of any information, apparatus, product or process disclosed, or represents that its use would not infringe privately-owned rights. 
Using the self-consistent solutions of the Eliashberg theory (1), we discuss in this paper the limitations on the superconducting critical temperature $T_{c}$ of isotropic superconductors. It was observed ${ }^{(2)}$ that the maximum $T_{c}$ of alloys in the transition metal (TM) series is given by the relation $T_{c} \lesssim k \frac{T_{m}}{M}$ ( $k$ is a constant, $T_{m}$ is the melting temperature from the solidus, and $M$ is the average ionic mass). We show that this empirical relation can be explained by Leaven's ${ }^{(3)}$ least upper bound on $T_{c}$. However, it is necessary to remark that Leaven's result is consistent with Allen's approximate $T_{c}$ equation, once the area $A$ of the electron-phonon spectral function $\alpha^{2} F(\omega)$ is fixed. The differences in the bound values are within two percents. Leaven's result can be expressed in the form $T_{c} \lesssim \frac{C\left(\omega^{*}\right)}{2} \frac{\eta}{M} \cdot \frac{\langle\omega\rangle}{\left\langle\omega^{2}\right\rangle}$, where $\eta$ and the frequency moments are defined in the usual way, $C(\mu *)$ is a $\mu^{*}$ dependent constant. For the class of alloys considered in reference $2, \frac{\eta\langle\omega\rangle}{\left\langle\omega^{2}\right\rangle} \sim \frac{\eta}{\theta_{\mathrm{D}}}$ scales well with $\mathrm{T}_{\mathrm{m}}$. The errors in this approximation are at most within a. few percents. Thus Poon and Johnson's maximum $\mathrm{T}_{\mathrm{c}}$ relation is obvious. Leaven's result is good for analyzing the $T_{c}$ trend in a particular class of alloys, when the trend of $A$ is known. To study the possibility of obtaining high $\mathrm{T}_{c}$ materials, it might be more informative to consider the fundamental atomic parameter $\eta$, since it depends explicitly on the self-consistent ionic potentials. We also prefer using Allen's approximate $\mathrm{T}_{\mathrm{c}}$ equation.

We first discuss the case of d-band isotropic superconductors. The asymptotic critical temperature can be expressed ${ }^{(3)}$ in the form $\mathrm{T}_{\mathrm{c}} \rightarrow 0.15(\eta / \mathrm{M})^{\frac{1}{2}}\left(\mu^{*}=0.1\right)$ as $\lambda \rightarrow \infty$. If we take $\eta \sim 12 \mathrm{eV} / \AA^{2}$, the maximum value expected based on cohesive energy arguments ${ }^{(2)}$, and a small value of $M=50$ amu for $T M$ elements; then 
$\mathrm{T}_{\mathrm{c}} \rightarrow 60^{\circ} \mathrm{K}$ as $\lambda \rightarrow \infty$. Experimentally, $\lambda$ is limited to order of unity because $\left\langle\omega^{2}\right\rangle \rightarrow 0$ signifies a lattice instability. However, using an expression of the form ${ }^{(4)}\left\langle\omega^{2}\right\rangle=\left\langle\Omega^{2}\right\rangle-2\langle\Omega R e \Pi\rangle$ only gives the condition for $\left\langle\omega^{2}\right\rangle \rightarrow 0$ or $\dot{\lambda} \rightarrow \infty$. Metallurgically, once a phase transformation occurs, $\left\langle\omega^{2}\right\rangle$ again sets on some finite values. It might be more useful to consider the relation $\left\langle\omega^{2}\right\rangle \approx \frac{\omega_{M}^{2}}{\langle\epsilon(q, \omega)\rangle}$ for the jellium model, where $\omega_{M}$ is the ion plasma frequency, and $\epsilon(q, \omega)$ is the linear dielectric function of the medium. It is found that ${ }^{(5)}$ by taking the empirical static dielectric function of Bennemann and Garland ${ }^{(6)}$, the values of $\left\langle\omega^{2}\right\rangle$ for $\mathrm{TM}$ elements and $\mathrm{Nb}_{3} \mathrm{Sn}$ scale well with the numerical results of reference 3 . One can show that $\langle\varepsilon(q, 0)\rangle$ is applicable to $\mathrm{d}$-band isotropic superconductors in general. (5) The most important parameter in $\langle\epsilon(q, 0)\rangle$ is the density of states $N\left(\varepsilon_{f}\right)$. For a given $\eta$ $\left(\right.$ say $\sim 10 \mathrm{eV} / \AA^{2}$ ) a high value of $\lambda$ is determined from a small $\left\langle\omega^{2}\right\rangle$ (or large $\left.N\left(\varepsilon_{\mathrm{f}}\right)\right)$.

It was shown in reference 4 that $\left\langle\omega^{2}\right\rangle \rightarrow 0$ as the product $\omega_{c} N\left(\epsilon_{f}\right) \rightarrow \sim 4$ states/atom, where $\omega_{c}$ is a cutoff frequency. This result seems to be quite general for tight-binding metals. (5) For metals, the value of $\omega_{c}$ cannot be significantly less than the intra-atomic Coulomb interaction, which is the order of a few eV. (7) Moreover, this lattice instability condition does not take into account the Gibbs free energies of the different competing phases, which might set a even more stringent condition on $N\left(\varepsilon_{f}\right)$. It is reasonable to assume $N\left(\varepsilon_{f}\right) \geqq 3$ states/eV atom. Comparing the value of $\left\langle\omega^{2}\right\rangle$ obtained this way together with $\eta \sim 10 \mathrm{eV} / \AA^{2}$ to the case of bad superconductors (e.g. Mo, W), we get $\lambda \leqslant 2-3$. For the $3 d$ series and some intermetallics, 
we might face another type of instability, namely ferromagnetism. In this case, the classical Slater-Stoner condition $N\left(\varepsilon_{\mathrm{f}}\right) \delta E \lesssim I$ sets an upper limit on $N\left(\epsilon_{f}\right)$, where $\delta E$ is the effective exchange energy. Usually, $\delta \mathrm{E} \sim 0.5 \mathrm{eV}$ for the $3 \mathrm{~d}$ series and is smaller for the $4 \mathrm{~d}$ and $5 d$ series. (7) The limit on $\left\langle\omega^{2}\right\rangle$ is again obvious and $\lambda$ does not seem to exceed the value obtained from lattice instability condition.

Actually, the difficulty for increasing $T_{c}$ when $\lambda \gtrsim 1$ is obvious from the approximate $T_{c}$ equation. In fact, the derivative $\frac{d T_{c}}{d \bar{\lambda}}$ reaches a maximum around $\lambda \sim 1$ and then tails off for larger $\lambda\left(\mu^{*} \sim 0.1\right.$, constant $\left.\eta\right)$. By taking $\eta \sim 10 \mathrm{eV} / \AA^{2}, \mu^{*} \sim 0.1$ and $\lambda \lesssim 3$, a maximum $T_{c}$ of $\sim 30^{\circ} \mathrm{K}$ is obtained assuming an Einstein spectrum. However, we must also consider the possibility of enhancing $\mu^{*}$ and thus lowering $T_{c}$ because it is an increasing function of $N\left(\varepsilon_{f}\right)$. Tunneling experiments on TM elements and compounds are needed to study the effects of the pair $\left(\lambda, \mu^{*}\right)$ on $T_{c}$. The $T_{c}$ value for d-band superconductors obtained here might have been a marginal value. The metallurgical feasibility of particular phases has been ignored.

For the simple metals, the light elements (e.g. metallic phases of $H, B e$ and $C$ ) are potentially high $T_{C}$ superconductors. The $T_{C}$ benefits from the small mass even though $\eta\left(\lesssim 2.5 \mathrm{eV} / \AA^{2}\right)$ is small. The small $\eta$ is universal of the one-OPW approximation of the Fermi surface. To obtain larger $\eta$ might require a multiple-OPW approximation ${ }^{(8)}$, which signifies a tendency towards covalent-metallic instability. Although, this does not increase $\lambda$ appreciably since the Debye temperatures are high, yet the fact that $\lambda \lesssim 0.5 \frac{\mathrm{dT} c}{\mathrm{~d} \lambda}$ still increasing as mentioned earlier) is promising in further enhancing $T_{c} \cdot A T_{c}$ as high as $\sim 11^{\circ} \mathrm{K}$ has been obtained in metastable Be films. (9) For intermetallics 
from the fourth period and higher in the periodic table, it was observed ${ }^{(2)}$ that the maximum $\mathrm{T}_{\mathrm{c}}\left(\lesssim 10^{\circ} \mathrm{K}\right)$ is independent of the melting temperature. It is reasonable to expect higher values of $T_{C}$ from the lower periods with small atomic mass.

ACKNOWLEDGMENT - The author wishes to thank Professor Pol Duwez for support throughout this work. 


\section{REFERENCES}

*Work supported by the Energy Research and Development Agency under Contract No. AT(04-3)-822.

1. P. B. Allen and R. C. Dynes, Phys. Rev. B 12, 905 (1975).

2. S. J. Poon and W. L. Johnson, Phys. Rev. B 12, 4816 (1975).

3. C. R. Leavens, Solid State Comm. 17, 1499 (1975).

4. I. R. Gomersall and B. L. Gyorffy; Phys. Rev. Lett. 33, 1286 (1974).

5. S. J. Poon, unpublished.

6. K. H. Bennemann and J. W. Garland, Theo'ry, d-Band Metals; in 'Superconductivity in d-and f-Band Metals', ed. D. H. Douglass (AIP, New York, 1972).

7. J. Friedel, 1967 Proc. Int. School of Physics 'Enrico Fermi' W. Marshall ed. (New York, Academic Press).

8. W. A. Harrison, 'Pseudopotentials in the Theory of Metals' 1966 , W. A. Benjamin Inc., New York.

9. N. E. Alekseevskii, V. I. Tsebro, and E. I. Fillippovich, Zh. Eksp. Teor. Fiz. Pis'ma Red. 13, 247 (1971) [JE TP Lett. 13, 174 (1971)]. 